\title{
Variability of the internal tide on the southern Monterey Bay continental shelf and associated bottom boundary layer sediment transport
}

\author{
Kurt J. Rosenberger*, Curt D. Storlazzi and Olivia M. Cheriton \\ U.S. Geological Survey \\ Pacific Coastal and Marine Science Center \\ 400 Natural Bridges Drive \\ Santa Cruz, CA 95060 \\ *corresponding author \\ krosenberger@usgs.gov \\ 831.460 .7535
}




\title{
Keywords
}

Internal tide variability; Monterey Bay; upwelling; relaxation; suspended sediment transport

\begin{abstract}
A 6-month deployment of instrumentation from April to October 2012 in 90 m water depth near the outer edge of the mid-shelf mud belt in southern Monterey Bay, California, reveals the importance regional upwelling on water column density structure, potentially accounting for the majority of the variability in internal tidal energy flux across the shelf. Observations consisted of time-series measurements of water-column currents, temperature and salinity, and near-bed currents and suspended matter. The internal tide accounted for $15-25 \%$ of the water-column current variance and the barotropic tide accounted for up to 35\%. The subtidal flow showed remarkably little shear and was dominated by the 7-14 day band, which is associated with relaxations in the dominant equatorward winds typical of coastal California in the spring and summer. Upwelling and relaxation events resulted in strong near-bed flows and accounted for almost half of the current stress on the seafloor (not accounting for wave orbital velocities), and may have driven along-shelf geostrophic flow during steady state conditions. Several elevated suspended particulate matter (SPM) events occurred within 3 $\mathrm{m}$ of the bed and were generally associated with higher, long-period surface waves. However, these peaks in SPM did not coincide with the predicted resuspension events from the modeled combined wave-current shear stress, indicating that the observed SPM at our site was most likely resuspended elsewhere and advected along-isobath. Sediment flux was almost equal in magnitude in the alongshore and cross-shore directions. Instances of wave-current shear stress that exceeded the threshold of resuspension for the silty-clays common at these water depths only occurred when near-bed orbital velocities due to long-period surface waves coincided with vigorous near-bed currents associated with the internal tide or upwelling/relaxation events. Thus upwelling/relaxation dynamics are primarily responsible for variability in the internal tide, as well as transport of nearbottom sediment in the mid-self mud belt during the relatively quiescent summer months.
\end{abstract}




\section{Introduction}

Numerous recent studies have demonstrated the significance of the semidiurnal internal tide on circulation, transport, and biological processes in the Monterey Bay region. Internal tides have been shown to be important in the formation of thin layers (McManus, et al, 2005) and in the cross-shelf transport of plankton (Shanks, et al, 2014). In the nearshore regions, shoaling internal tides provide a mechanism for vigorous mixing and sediment transport (Storlazzi et al, 2003; Woodson et al, 2012; Walter et al, 2012; Cheriton et al, 2014).

Initial studies indicated Monterey Submarine Canyon (MCS) as a generation site for the $\mathrm{M}_{2}$ baroclinic tide in the bay (Petruncio et al, 1998). More recent modeling studies show that the primary source region for the generation of internal tides for the Monterey Bay area is more likely the Sur Ridge/Platform complex to the south of the bay (Carter et al, 2005, 2010; Johnston et al, 2011; Jachec, 2012; Kang 2012) and that MSC acts as a conduit for this baroclinic energy flux into the bay (Kunze, et al, 2002; Hall et al, 2002; Wain et al, 2013). Few studies have focused on measuring the propagation across and/or generation of internal tides on the outer continental shelf of Monterey Bay, however. Measurements of microstructure profiles conducted by Carter (2005) showed enhanced dissipation and diapycnal diffusivities associated with both remotely and locally generated internal waves at the shelf break, but the measurements were somewhat limited in space and time.

Internal tides in the ocean are notoriously ephemeral in nature, particularly on the continental shelf, and there are a multitude of potential reasons for observed variability in energy. Nash et al (2012) surveyed data from different regions of the world's oceans, and found the internal tide to be difficult to predict. They point to a variety of reasons for variability; the remote nature of potential generation sites, interference and Doppler shifting between internal tides propagating from variable generation regions as well as interference between remotely and locally generated internal tides, and steering and refraction by complex bathymetry. Perhaps one of the most important reasons for temporal variability of the internal tide observed on the continental shelf, however, is the variability of the current and density structure of the ocean, with which a remotely generated internal tide must interact. 
Most modeling studies use a single density profile to model the conversion of energy from barotropic to baroclinic (Hall et al, 2014a). In reality, the structure of water column stratification is highly variable in both space and time, particularly in the vicinity of strong upwelling, as is the case in Monterey Bay. There has been renewed interest in how the interaction of the internal tide with variable density structure can affect its propagation through the ocean (Zhao et al, 2012, Hall et al, 2014a,b; Kerry, et al, 2014). We hypothesize that upwelling is important in the propagation of internal tides across the Monterey Bay shelf by enhancing stratification, thereby providing a waveguide for internal waves.

In this paper we examine the variability of the internal tide on the continental shelf of southern Monterey Bay with a 6-month record of water column currents and temperature and salinity, and relate these measurements to the general circulation and upwelling/relaxation dynamics. We also explore sediment dynamics on this portion of the shelf to determine if and under what conditions sediment resuspension and transport occurs on the mud belt of southern Monterey Bay. We will show that while the internal tide may be important for transport of material on the inner shelf, the subtidal flow, which is predominantly wind-driven, is not only responsible for propagation of the internal tide, but also primarily responsible for near-bottom transport on the deeper portions of the shelf.

\section{Study Area}

The southern portion of Monterey Bay consists of a broad, flat shelf bounded to the north and west by MSC, with a shelf break at approximately $110 \mathrm{~m}$ (Figure 1). The seafloor geology consists of modern sands in the shallower reaches, fining to silts and clays in deeper water. The primary source of sediment to the shelf in south Monterey Bay is the Salinas River, which discharges on average $1,308,125 \mathrm{~m}^{3}$ of sediment per year (Griggs and Hein, 1980). A distinct mud belt lies on the central to northern part of the shelf, with moment mean grain size from $63 \mu \mathrm{m}$ to $3.9 \mu \mathrm{m}$ in water depths ranging from 30 to $100 \mathrm{~m}$. The eastern boundary of the mud belt follows isobaths; the southern boundary of the belt runs cross-isobath, with sands predominant in deeper water to the 
south of the mud belt (Edwards, 2002). The seafloor geology of the shelf break seaward of the mud belt exhibits sands and rock outcrops.

The surface wave climate in Monterey Bay is bimodal during the summer months; short period northwest wind swell ( $<10 \mathrm{~s}$ ) driven by the strong northwest regional winds and longer period southwest swell (>14 s) that originates from storms in the Southern Ocean (Xu, 1999).

In order to distinguish between local bathymetry surrounding the study area and the general coastline of California when discussing observed flow patterns, in this paper, 'along-shelf' refers to the orientation of the isobaths of the study area, whereas 'alongcoast' refers to the regional coastline of central California.

\section{Methods}

\subsection{Moored Instrumentation}

Time-series instrumentation was deployed on two platforms; a bottom boundary layer (BBL) tripod and a combined sub-surface/S-tether surface taut-wire mooring at a location of $36.730^{\circ} \mathrm{N}, 121.904^{\circ} \mathrm{W}$ in $90 \mathrm{~m}$ water depth (Table 1). Platforms were deployed on 10 April 2012 and recovered on 30 October 2012 aboard the $R / V$ Point Sur. A Sontek Hydra acoustic Doppler velocimeter (ADV) was placed 0.7 meters above bottom (mab), thereby setting the sampling volume at $0.5 \mathrm{mab}$. This instrument also logged data from a high-resolution Paroscientific Digiquartz pressure sensor, a Wetlabs C-star 25-cm path-length transmissometer, and a Campbell Scientific OBS-3+ $880 \mu \mathrm{m}$ optical backscatter sensor (OBS), also set at 0.5 mab. The instrument was set to record all data at $2 \mathrm{~Hz}$ for $60 \mathrm{~s}$ every $3 \mathrm{~min}$ in an effort to capture high-frequency internal wave activity near the seabed. The tripod had two Seabird SBE-37 temperature and salinity sensors, at 1.0 and 2.4 mab. Finally, a Teledyne RD Instruments $300 \mathrm{kHz}$ Workhorse acoustic Doppler current profiler (ADCP) was mounted at the top of the tripod at 2.9 mab, measuring profiles of currents in 2-m high vertical bins from 7.1 mab to the surface every 3 min (60 pings per ensemble at 1Hz). Six high-resolution RBR Solo thermistors 
were mounted at 10-m intervals on the taut-wire sub-surface mooring from 10 mab to 60 mab; a Seabird SBE-37 temperature and salinity sensor was mounted at 70 mab.

The two OBS sensors each had a mechanical wiper attached, set to wipe the face of the sensor every $6 \mathrm{~h}$, so as to prevent biofouling. The transmissometer did not have an anti-fouling mechanism, however, and the record begins to show the signs of biological fouling about halfway through the deployment. This fouling was corrected, however, using a step-wise linear de-trend algorithm. The calibration of the upper OBS sensor was problematic, and is therefore not shown.

\subsection{Analysis of Internal Tidal Currents}

The variability of the baroclinic tidal currents over the 6-month deployment was investigated following a method utilized by Noble, et al. (2009) and Nash, et al. (2012). First, the current velocity time series ( $U$ and V) were band-pass filtered with a $4^{\text {th }}$ order Butterworth filter, with a window of 6 to $16 \mathrm{~h}$ to remove subtidal and high frequency variability and isolate the tidal band. Secondly, a tidal harmonic fit of the depth-averaged current was subtracted from each component of the band-passed data to remove the barotropic tide, and lastly the record was averaged with a 1-h box-car filter and subsampled for ease of viewing and further analysis.

\subsection{Sediment Transport Model}

A one-dimensional (1-D) BBL vertical combined wave-current interaction sediment transport model (STM) was used to evaluate the relative contribution of waves and currents to the stress on the seabed and the potential for resuspension and transport of sediment from the site (Smith and McLean, 1977; Wiberg and Smith, 1987; Madsen, 1994; Wiberg et al., 1994; Harris and Wiberg, 1997; Wiberg et al., 2002; Ferre et al., 2010). The model requires as input the near-bed current velocity, orbital velocities due to surface waves, surface wave direction and angular frequency, and an estimate of the bottom roughness, $k_{N}$, the Nikuradse roughness $\left(30 * z_{0}\right.$, the internal hydraulic roughness length). For the near-bed currents, we used the 3-min data from the ADV (0.5 mab). For a bottom roughness, $k_{N}$, we used $d_{90}$ from the collected seafloor sample, which is $54.3 \mu \mathrm{m}$, which resulted in combined wave-current shear stresses comparable to other studies in 
similar water depths on the California continental shelf (Ferre and Sherwood, 2010, Cacchione et al, 1994).

We used surface wave directional spectral data from a nearby National Oceanographic and Atmospheric Administration buoy 46042 (http://www.ndbc.noaa.gov/station_page.php?station=46025) to calculate the near-bottom wave-orbital velocities following Wiberg and Sherwood (2008), as we did not have direct measurements of near-bottom wave-orbital velocities. We interpolated the surface wave time series from the basic time interval of $1 \mathrm{~h}$ to the time interval of the BBL instruments, which was 3 min. While some shadowing of waves by points at the northern and southern entrances to the Bay may occur, Xu (1999) notes that even the near-shore regions of southern Monterey Bay (<15 m water depth) experience long period south swell (20 s) in the summer months, albeit at a somewhat reduced amplitude compared to the northern Bay. Thus we are confident that wave data from the NOAA buoy is representative of the wave climate at our site at a depth of 90 m near the shelf break.

The STM provides as output the current friction velocity and the combined wavecurrent friction velocity, from which we calculated the shear stress, $\tau_{s}$ on the seabed due to the combined effects of surface waves and horizontal currents; these stresses are then applied to a reference sediment concentration at the seabed, which is estimated from the excess shear stress and the availability of sediment for, in this case, 5 grain-size classes. A sediment concentration profile is then calculated using an eddy viscosity profile that includes wave-current interaction, and by balancing the upward diffusion with downward settling of sediment in suspension. The sediment transport rate is then the volume in suspension multiplied by the velocity profile. The user inputs settling velocity for each sediment grain-size class; to account for flocculation of fine-grained sediment, the settling velocity for the three finest classes (31 $\mu \mathrm{m}, 7.8 \mu \mathrm{m}$ and $1.5 \mu \mathrm{m}$ ) was set to that of the second, $125 \mu \mathrm{m}$.

In order to determine the excess shear stress, a value of critical shear stress, $\tau_{c r}$, needs to be calculated or chosen for each size class. For the coarser-grained fractions (D $=500,125$ and $31 \mu \mathrm{m}$ ), the critical stress for mobilization of the sediment was calculated following Wiberg and Smith (1987). Determining a critical shear stress for fine-grained sediment is much more difficult, however, due to inter-particle bonding and bed armoring 
during wave events. Ferre and Sherwood (2010) conducted shear stress experiments on sediment cores obtained from the Palos Verdes shelf using a Gust erosion chamber (Gust and Muller, 1997) to determine critical shear stress for finer-grained sediment. We used Ferre and Sherwood's (2010) value of 0.09 Pa for the two finest sediment classes at our site $(7.8$ and $1.5 \mu \mathrm{m})$, as the sediment composition at our site closely matched that of the Palos Verdes shelf (Table 2).

We calculated the concentration of sediment suspended by the applied stresses using the formulation of Smith and McLean (1977) to compare the model to measured suspended sediment:

$$
C_{r e f}=\left[c_{b} y_{0} s /\left(1+y_{0} s\right)\right]_{s}
$$

where $c_{b}$ is the bed sediment concentration (1-porosity), $\mathrm{S}$ is the fraction of excess shear stress that equals $\left(\tau_{s^{-}} \tau_{c r}\right) / \tau_{s}, \gamma_{0}$ is a resuspension coefficient, and $\rho_{s}$ is sediment grain density. A value of 0.0002 was chosen for $\gamma_{0}$ following Ferre and Sherwood (2010), which gave the best fit between measured and modeled concentrations during the more significant events.

\subsection{Calibration of optical sensors}

Sediment collected at the site by Van Veen sediment grab was analyzed for detailed grain-size distribution and was used to calibrate data from the optical instruments on the tripod into units of sediment concentration in $\mathrm{mg} / \mathrm{l}$. Each sensor was placed in a graduated, cone-bottomed tank with a recirculating pump, and a known mass of sediment was placed in a known volume of water while readings were taken from the sensor, averaged over $1 \mathrm{~min}$ of active pumping.

\section{Results}

4.1 Winds, Water Column Structure, and Subtidal Flow Patterns 
The complete 6-month time series shows the importance of the wind forcing on the water column stratification and general flow (Figure 2). Large-scale gradients in surface atmospheric pressure between the North Pacific Ocean and central Nevada drive strong equatorward winds along the California coast in spring and summer, which, in turn, drive the upwelling at prominent points along the coast. The strong equatorward winds relax or reverse at somewhat regular intervals, and it is well documented how these wind shifts can influence water-column structure and flow in Monterey Bay (Ramp, 2005). In addition to the regional wind field, daily heating of the inland valleys of California drive a locally strong diurnal sea breeze, which has also been shown to influence water-column structure (Woodson, 2007). During our deployment period, events occurred with some regularity, where, on average, every $10 \mathrm{~d}$ the equatorward winds reduced in speed or reversed. The regional along-coast wind (which is cross-shelf at our site) power spectrum exhibits a dominant peak in the diurnal band, with the next most significant peak centered at 8 days, at half the amplitude (not shown).

During periods of upwelling-favorable winds (indicated by strong downcoast winds, blue line in Figure 2(a)), intrusions of cold water occurred in the lower water column at our study site, but when the winds relaxed or reversed, there was a sudden warming through the water column resulting in a depression of the isotherms. There were numerous relaxation events during the deployment period, 7 of which resulted in a depression of isotherms by over $50 \mathrm{~m}$ (dark grey bands). Several other relaxation events occurred that resulted in smaller isotherm depressions, but could still influence the circulation (light grey bands). The largest warming events occurred during periods when the winds fully reversed to poleward, downwelling-favorable conditions. Wind speeds during these events are low and short in duration compared to the upwelling-favorable periods. Thus, it is hard to say if there was, in fact, downwelling occurring in the region. Rather, water-column warming during a relaxation event was more likely due to the return of ambient water masses to the site when the cold, upwelled water exited (water column flow is typically along-isobath and poleward at these times). After a relaxation event, when upwelling-favorable equatorward winds resumed, water-column flow was generally equatorward, suggesting that the cold, upwelled water originated from northern Monterey Bay, and not south of Monterey Bay, such as Point Sur. The water column 
gradually warmed over the course of the deployment, particularly toward the end when the winds reduced in strength.

The record of subtidal currents was generated with a 40-h Butterworth low-pass filter (Figure 2). The subtidal flow was dominated by the along-shelf component, with remarkably little shear through the water column (the along and cross-shelf directions were determined by depth averaging the principal axis direction from a principal components analysis of the ADCP data). There appeared to be a slight tendency toward equatorward flow, but notable poleward flowing events were present, often associated with a relaxation event, although not exclusively. The cross-shelf component was predominantly onshore at the surface, and offshore at depth, which is consistent with a dominant regional wind that blows onshore at this site.

Power spectral density of the subtidal currents shows a dominant broad peak in the wind band centered around $200 \mathrm{~h}$ (8.3 d), with secondary peaks near $125 \mathrm{~h}$ and $88 \mathrm{~h}$ (5 and $3.7 \mathrm{~d}$, respectively; Figure 3a and 3b). A recent study on the circulation of the California Current System (CCS) using RAFOS floats noted that the dominant period of eddies in the CCS was approximately 5 d (Collins, et al, 2013). Rotary spectra of the water column currents at our site shows that the peak at $5 \mathrm{~d}$ was predominantly clockwise in the surface layers, and counter-clockwise at depth (Figure 3c and 3d). The peak at $5 \mathrm{~d}$ was observed in the spectra of the unfiltered temperature data as well, particularly at the surface and bottom, and accounted for a higher percentage of the energy than the semidiurnal tides (not shown).

A 3-d oscillation has been observed in Monterey Submarine Canyon by $\mathrm{Xu}$ and Noble (2009), and therefore may be related to the peak at $3 \mathrm{~d}$ that we observed. The authors, however, were unable to account for the origin of this oscillation.

\subsection{Barotropic Tides}

A harmonic tidal analysis of the ADCP surface track data shows the major constituents of the surface tide to be $\mathrm{M}_{2}, \mathrm{~S}_{2}, \mathrm{O}_{1}$, and $\mathrm{K}_{1}$, with some contribution from side lobe lines such as $\mathrm{P}_{1}$ and $\mathrm{N}_{2}$ (Pawlowicz et al., 2002). The amplitude is almost identical to that of Monterey Harbor approximately $8 \mathrm{~km}$ to the south, and there was little phase 
difference between the two sites. A harmonic tidal analysis was performed on the vector ADCP data at each depth level (Pawlowicz et al, 2002). Current ellipses from the harmonic analysis reveals that the amplitudes of the major constituents were consistent with depth $(\leq 6 \mathrm{~cm} / \mathrm{s})$, and the ellipse orientations were along-isobath throughout the water column.

\subsection{Internal Tides}

In addition to wind-driven patterns, undulations of the isotherms from the internal tide are ubiquitous throughout the measurement period (Figure 2). These internal tide fluctuations had amplitudes of 10-20 m, with larger events reaching $30 \mathrm{~m}$, and occurred at all water depths.

Time-averaged profiles of internal tidal currents were near zero throughout the water column for both the along and cross-shelf (not shown). Magnitudes of the internal tide were slightly stronger in the along-shelf direction. The structure of the cross-shelf internal tide was closer to a mode-2 type profile, with higher values at the surface and bottom. In the upper water column, the diurnal, baroclinic, and barotropic currents were approximately equal in variance (Figure 4). Deeper in the water column, the cross-shelf portion of the internal tide represents a higher percentage of the variance of the currents at this site than both the along-shelf baroclinic (less than 20\%) and the barotropic tide (less than 30\%), reaching 70\% near the seabed. Thus the cross-shelf component of the internal tide could be important in the transport of material in this shelf region, whether by resuspension or advection. It should be noted that, because some diurnal energy remained in the internal record, the variance of the baroclinic records may be artificially enhanced.

The magnitude of the internal tidal currents show a high degree of variability in both depth and time during the 6-month time series (Figure 5). In addition, the internal tidal current amplitudes were as strong, if not stronger, near the seabed than higher in the water column. Periods of enhanced internal tidal activity were more concentrated in the first half of the record, from April (Year Day 102) to the middle of August (Year Day 220). Although the along-shelf component generally had somewhat higher amplitudes, there were periods throughout the time series where one component was more dominant 
than the other (not shown). An example 5-day time series of the along- and cross-shelf internal tidal velocities is shown in Figure 6, demonstrating variability of the internal tidal amplitudes with both depth and time, even on short timescales. That the internal tide is predominantly semi-diurnal and comprises a larger percentage of the variance in the near-bottom layers is also clearly visible.

\subsection{Bottom-boundary Layer Currents and Suspended Sediment}

The acoustic Doppler velocimeter and three optical sensors on the bottommounted tripod recorded 4 months of currents and suspended sediment in the BBL. Although surface wave heights regularly exceed $3 \mathrm{~m}$ at this site in the summer, they were generally shorter-period wind waves generated by the strong regional winds (Figure 6). Occasionally longer-period swell from Southern hemisphere storms entered the region during spring through fall months, but the amplitude of these southerly wave events tended to be below $2 \mathrm{~m}$. There were two wave events that were higher in both wave height and period at the beginning of the record (14 and 18 April; Year Day 105 and 109), and this is reflected in the calculated wave orbital velocity. At our study site along the $90-\mathrm{m}$ isobath, the largest sustained near-bed wave-orbital velocities were approximately $15 \mathrm{~cm} / \mathrm{s}$, but the majority of observed longer-period wave events resulted in near-bed wave-orbital velocities that rarely exceeded $5 \mathrm{~cm} / \mathrm{s}$ (Figure 7). Both instantaneous and internal-tidally driven near-bed horizontal current speeds were consistently higher than wave orbital velocities. While elevated near-bottom currents were often associated with the passage of energetic internal waves, the strongest currents near the seabed were generally uncorrelated to the internal tides. So while the internal tides may have comprised a higher percentage of the variance near the seabed, the highest stresses due to currents on the seabed were correlated to lower-frequency events, such as shifts in water-column flow and structure associated with relaxation events in the winds, as is the case with the event on Year Day 170.

The two different optical sensors respond to varying grain-size distributions differently and this knowledge can help elucidate patterns of sediment resuspension and transport. Transmissometers have a stronger response to finer-grained material, whereas OBSs respond more strongly to coarser-grained material. Suspended particulate matter 
(SPM) data from the two optical sensors in the BBL do show somewhat different patterns. The transmissometer shows slightly elevated SPM through the record, suggesting the presence of a persistent bottom nepheloid layer, and spectra of these data show significant peaks at the diurnal and semidiurnal frequencies. The OBS shows more sporadic, shorter duration SPM peaks, some of which correspond to peaks in the transmissometer, but most of which do not. There were many more SPM peaks in the OBS record toward the end of the record, and it is thought these might be due to interference from the wiping mechanism, or biologic material such as kelp that was caught on the tripod leg and waved in and out of the sampling volume.

Local resuspension of sediment at the tripod location should result in elevated SPM in both sensors. This only occurred on select occasions, at the beginning of the record when there were larger wave events of longer period. To better understand the link between observed SPMs and stress on the seabed, we employed a 1-D BBL numerical sediment transport model.

\subsection{Application of the 1-D Bottom-boundary Layer Sediment Transport Model}

The numerical model predicted that sediment would be resuspended at this water depth on only a handful of occasions in the record, two of which were at the beginning of the study when there were elevated near-bottom orbital velocities due to longer period surface waves (Figure 7). Although it appears that larger surface waves are necessary to apply sufficient stress to resuspend sediment at the site, on average, currents comprised a greater percentage of the combined wave-current stresses. In addition, periods of higher current stress often corresponded to internal tide activity, as well as other sub-tidal processes.

A closer examination of the first event on Year Day 105 reveals much about the dynamics at this site (Figure 8). There is a clear offset in timing between the measured and modeled SPM. It should be noted that the concentrations reported here from the STM represent the modeled concentration at the level of the instrument at which measurements were made. The model predicted two separate sediment resuspension events ( $\sim$ Year Day 104.7-105.2 and 106-106.2), each of which coincided with periods of larger waves and stronger currents. During the first event on Year Day 104, measured SSC increased 
slightly, and then continued to increase after the modeled event ended, not reaching maximum values until half a day later when the currents shifted from southward to northward. Thus, it appears that SPM measured during that event were advected alongisobath from the south. Bearing in mind the uncertainty in the critical threshold for the resuspension of cohesive fine-grained sediment, the observed peaks in SPM during this event do correspond to peaks in modeled stresses, though less than our chosen critical threshold value of $0.09 \mathrm{~Pa}$. These peaks in stress also correspond to changes in current direction, however, so while we cannot exclude the possibility that local resuspension occurred at our measurement location, SPM appears to be due to advective fluxes.

On Year Day 106, when modeled stresses were above critical for fine-grain sediment, there was no corresponding increase in observed SPM during or after the event. These events on Year Days 104.5-106.5 are representative of the entire record, in that peaks in the observed SPM did not correspond to times when the modeled stresses predicted resuspension.

\section{Discussion}

5.1 Wind-driven Response: Influence of Upwelling/Relaxation Events on water column structure and flow

Two upwelling centers are located in close proximity to Monterey Bay: Point Año Nuevo, approximately $57 \mathrm{~km}$ to the north, and Point Sur approximately $46 \mathrm{~km}$ to the south; thus it is important to note that although we discuss upwelling favorable conditions, we do not mean that waters are being upwelled onto the shelf near our study site by Ekman flow. It has been shown that the tongue of cold water upwelled to the north can extend all the way across the mouth of Monterey Bay, onto the Point Sur platform, and at times fill Monterey Bay (Wang et al., 2011; Ramp et al., 2005; Rosenfeld et al., 1994). Therefore, the mechanism by which cold-water masses enter southern Monterey Bay differs from the classical upwelling scenario (Hickey, 1979) - rather than a tilting of the isotherms, the water mass approaches as a front. This, in turn, should influence the circulation in this part of the bay. 
During strong upwelling-favorable winds, the subtidal flow at our study site was along-isobath and equatorward (out of the bay) (Figure 2). Studies have shown that a jet can develop flowing south across the mouth of the bay during strong downcoast winds (Ramp et al, 2005). The observed equatorward flow could be the entrainment of bay waters into this jet, as was noted by Ramp et al. (2005) during a strong upwelling event. This could also be a geostrophic flow developing in response to the impinging upwelling front, which, again, is opposite to conventional geostrophic response to upwelling, such as the California Undercurrent. During upwelling-favorable winds, the cross-shelf component showed a slight net onshore flow near the surface and offshore flow near the bed.

As soon as winds begin to relax, flow reversed to poleward (into the bay), with one or two exceptions. Generally speaking, the strongest poleward flows were in response to the most significant relaxation events. Ramp et al. (2005) noted that during relaxation events, the Monterey Bay Eddy, a semi-permanent cyclonic feature that develops off the coast during the summer, translates toward the coast. The result of this translation is that the southern end of the eddy, which is flowing eastward, impinges upon the south coast of Monterey Bay and the Monterey Peninsula, flowing into the bay. Indeed, during extended relaxation events, a northward jet develops off the northern tip of the Monterey Peninsula, flowing into southern Monterey Bay, which is consistent with the poleward flows that we observed (Figure 2). Some of the more significant onshore flow events occurred during the larger relaxation events, which is also consistent with a jet entering the bay off the northern tip of the Monterey Peninsula. The fact that little water-column shear was observed in the along-shelf flow means that these features previously noted only at the surface translate down through the water column to the seabed.

5.2 Variability of the Internal Tide and potential for generation and/or breaking on the mud belt

Semi-diurnal internal tides propagated across this portion of the shelf consistently through the spring, summer and early fall, with significant variability of energy in time and depth. Although there was much overlap between periods of higher internal tide 
activity in the surface layers and bottom layers, there were periods when one superseded the other. Inconsistency in observed internal tidal energy could be due to variability in incident internal tide energy or variability in the local stratification, whether by providing a waveguide for internal waves to propagate, or by local generation. While we do not have data to assess the variability in incident baroclinic energy flux, we do have water column temperature data to explore the role that local stratification has on the propagation of internal tides across the shelf.

To assess water column stratification, the squared Brunt-Väisälä frequency $\left(N^{2}\right)$ was calculated for the upper half, the lower half, and the entire water column, using the formulation from Gill, 1982, where $N^{2}=-g / \rho \times d \rho / d z$. Data from the temperature and salinity sensors did not extend through the entire time series. Thus, average values from the mid water-column and bottom-mounted temperature and salinity sensors were used to calculate density. $N^{2}$ over the whole water column varied from 5.21e-05 to 1.67e$04 \mathrm{~s}-2$, with a mean of 8.6e-05 s-2, while ranges for the upper and lower water column were $3.6 \mathrm{e}-05$ to $2.2 \mathrm{e}-04$ and $1.6 \mathrm{e}-05$ to $2.1 \mathrm{e}-04 \mathrm{~s}-2$, with means of $1.1 \mathrm{e}-04$ and $6.2 \mathrm{e}-05$ s2, respectively.

Potential for generation and/or breaking of the internal tide on the shelf can be evaluated using the ratio of the bottom slope to the internal wave characteristic, which is a function of the frequency of the wave, the local Coriolis frequency, and the $N^{2}$ (Wunsch, 1975). Thus, for a given location, the only source of variability is $N^{2}$. Carter et al. (2005) showed that the slope of much of the deeper portions southern Monterey Bay shelf is critical for the generation or breaking of the semi-diurnal $\mathrm{M}_{2}$ tide at buoyancy frequency of 1e-04 s-2 or greater. Water-column buoyancy frequency at our site was less than this value on average; thus it does not appear that the internal tide is generated locally, nor does it break on this portion of the shelf. Indeed, this could explain the presence of the mud belt in these water depths of Monterey Bay (Cheriton et al., 2014).

In their analysis of critical slopes and buoyancy frequency for southern Monterey Bay, Carter et al. (2005) also showed that along the shelf break, just offshore of our measurement location, the slope is such that the critical buoyancy frequency for the $\mathrm{M}_{2}$ internal tide is between 1e-05 s $\mathrm{s}^{-2}$ and 1e-04 s-2, which is in the range of buoyancy frequency measured at our site. Assuming the buoyancy frequency profile does not 
change dramatically between our measurement location and the shelf break, breaking and/or generation of internal tides probably occurs at the shelf break, potentially accounting for the coarsening of sediment (and presence of rock outcrops) noted along the shelf break (Edwards, 2002).

Though there did not appear to be correlation between average $N^{2}$ for portions of the water column and internal tide activity on the shelf, the structure of the profile is important (Rainville and Pinkel, 2006). Although internal waves will propagate in a continuously stratified ocean, a strong pycnocline resulting in a peak in the buoyancy frequency profile will facilitate propagation horizontally. We examined the structure of $N^{2}$ (averaged over a tidal period) during periods of enhanced internal tide activity (outlined in Figure 5) as compared to the average profile for the deployment period. Although the average profile does not contain a peak mid-depth, during most periods of elevated internal tidal currents, the buoyancy frequency profile demonstrated well developed peaks, mostly, but not exclusively, in the upper water column (Figure 9). This is clearly due to enhanced stratification by upwelling waters impinging onto the shelf at the bottom.

The pycnocline was most well developed toward the beginning of the record, when upwelling favorable winds were strongest and most sustained, and cold, upwelled waters encompassed the lower half of the water column, as in periods A, B, and C displayed in Figures 5 and 9. The fourth period, D, from Year Day 182 to 187, showed some of the strongest internal tidal currents through the water column, but the $N^{2}$ profile did not appear have a well-defined peak. However, we have less resolution in temperature data in the upper water column, as there was no thermistor at $10 \mathrm{~m}$ water depth. Thus it is likely that the pycnocline developed in the upper $20 \mathrm{~m}$ of the water column during this period, and we simply cannot resolve it. This period and the next occurred after a relaxation event, when upwelling winds were again increasing, though not as strong as in previous periods.

The last period occurred at the end of the upwelling season, when stratification began to develop near the surface as a result of insolation-induced surface heating. Interestingly, the observed internal tidal energy at this time was less than the first half of the record. Anecdotally, one would expect more enhanced stratification, and thus 
increased baroclinic energy flux, during the warmer, more quiescent summer months when surface waters warm up, but this does not appear to be the case. Instead, warming occurs through the entire water column, and therefore stratification is not as significant as it would be if warming were limited to the surface waters (or if cold, upwelled water was intruding from below, as is the case in the first half of the record).

\subsection{Sediment Resuspension, Seabed Stress, and Fluxes}

\subsubsection{Sediment resuspension on the mid-shelf mudbelt}

Although the near-bed optical sensors measured numerous elevated SSC events, only select few SSC events demonstrated characteristics of local resuspension. Even still, the results of the sediment transport modeling suggest that these select events were the result of advection of sediment resuspended elsewhere on the shelf. The two largest events (Year Day 105 and Year Day 106) occurred at the end of the winter storm season, when larger, longer-period waves were sufficiently energetic to mobilize fine-grained sediment from the seabed. Assuming that flow in winter is predominantly along-shelf, net sediment transport would similarly be along-shelf. Xu et al. (2002) showed that the bulk of sediment transport on the northern Monterey Bay shelf occurred in winter and was predominantly upcoast to the northwest and slightly offshore. In summer, there was substantially less total sediment transport, and the net flux direction was downcoast to the southeast.

The internal tide contributed to elevated near-bottom currents throughout the record. Although not energetic enough to resuspend seabed sediment alone, the stress due to near-bed internal tidal currents was often requisite for the combined surface wavecurrent shear stress to exceed resuspension thresholds. We can therefore hypothesize that for the shelf region inshore from our site, as wave-orbital velocities increase, the presence of internal tidal currents elevated the stress above the critical threshold for resuspension. Although this is not particularly surprising, it means that the inshore boundary of the mud belt is most likely farther offshore than a simple ocean surface wave model would dictate.

The sediment transport model shows that on numerous occasions, currents near the seabed were almost high enough to resuspend cohesive fine-grained sediment, using the critical shear stress for fines determined through stress tests on sediment cores. If we 
use the formulations of Wiberg and Smith (1987), the critical shear stress to resuspend fine silt $(7.8 \mu \mathrm{m})$ is $0.023 \mathrm{~Pa}$, which the currents alone at our site often exceeded. Thus, currents were often strong enough to at least maintain sediment in suspension, which concurs with the observations of the transmissometer, which showed pulses of sediment in suspension.

There is no clear directionality to the near-bottom internal tidal currents at our study site, as is often the case on continental shelves (Noble et al., 2009), and thus this process alone probably does not contribute to a net flux of sediment in one direction or another. Indeed, even the along- and cross-shelf components are near equal in variance near the bottom, resulting in a more circular distribution.

Despite the fact that the internal tide comprised the highest percentage of variance of the near-bed currents, some of the strongest near-bed currents occurred during relaxation events, such as the one centered around Year Day 170, when near-bed currents exceeded $25 \mathrm{~cm} / \mathrm{s}$ which results in stresses high enough to resuspend fine-grained sediment. Since the internal tide does not show preferential steering, it follows that the wind-driven circulation is most responsible for the redistribution of sediment on the shelf.

\subsubsection{Partitioning of stresses on the seabed}

The STM showed that although stresses rarely exceed the critical threshold for resuspending cohesive fine-grained sediment during this time of year, the currents dominated the stress on the seabed. Although the model makes it possible to examine the relative importance of currents versus waves, it does not address other processes, such as turbulence. We were not able to assess the importance of turbulent stresses on the seabed as our data were derived from current velocities averaged over a 2-min sampling period, once every $3 \mathrm{~min}$. Higher frequency measurements obtained over longer periods would be necessary to achieve this (Shaw and Trowbridge, 2001).

The bulk of the variance in the water-column currents was comprised of the internal tide and subtidal flow. To examine their relative importance on the stress on the seabed, a simple quadratic drag stress was calculated $\left(\tau=\rho_{v:}: C_{d}+U^{*}\right)$ where $\rho_{w}$ is the density of the water, $U$ is the velocity data from the bottom bin of the ADCP and $C_{d}$ is the drag coefficient; we used a $C_{d}$ of 0.005, per Lentz et al. (1994). Using the bottom-bin 
subtidal and internal tide currents, we applied a reduction factor to fit those data to the depth-level of the ADV, calculated the stress, and compared each to the total stress (Figure 10). The internal tide comprised $29 \%$ of the total current stress, while the subtidal flow comprised $49 \%$. We already demonstrated that the low frequency flow comprises a higher percentage of the variance; however, the magnitudes of the low frequency stresses were often higher, resulting in higher stresses. There were several low-frequency events that exceeded the theoretical critical threshold for resuspension for the fine-grain seabed sediment at this site. Thus the low frequency flow appears to be more important for sediment transport than the internal tide, both in terms of resuspending sediment and net flux.

\subsubsection{Sediment flux}

We estimated the total observed transport of sediment per unit area of seabed at the study site by multiplying the calibrated transmissometer SPM by the along- and cross-shelf velocities from the near-bottom current meter for the $114 \mathrm{~d}$ that the instruments were collecting data. The bulk transport was 189.9 metric tons (mt) offshore and $53.2 \mathrm{mt}$ downcoast along-isobath to the southwest, with a net transport of $197.3 \mathrm{mt}$ at $254^{\circ}$ degrees. Given the difficulty in correcting for bio-fouling of the transmissometer, we also calculated transport for just the initial $46 \mathrm{~d}$ of the deployment. The sediment fluxes were $30.1 \mathrm{mt}$ offshore and $5.7 \mathrm{mt}$ downcoast to the southwest, with a net flux of $30.6 \mathrm{mt}$ at $259^{\circ}$, which results in a total sediment flux of $127.7 \mathrm{mt}$ for the entire deployment period of $192 \mathrm{~d}$.

These fluxes are notably higher than those reported by others on the California continental shelf (Xu et al., 2002; Ferre et al., 2010). The values reported in those studies, however, were derived by calculating sediment resuspension and transport at their respective locations, whereas we are reporting all suspended sediment observed to pass our instruments. The transmissometer data confirm the presence of a persistent bottom nepheloid layer, with SPM pulses at tidal periods, which have been observed elsewhere on the California continental shelf (Cacchione et al., 1986; Drake et al., 1987), in Monterey Bay (Cheriton et al., 2014), and Monterey Submarine Canyon (Xu et al., 2002). 
The direction of net transport, downcoast to the southwest, in conjunction with the previous observations that the sediment fines and thickens to the north and east of our study site (Edwards, 2002; Eittreim et al., 2002; Lewis et al., 2002) is consistent with the primary depocenter in the southern Monterey Bay mud belt a few km to the northeast of our site. The sediment in the mud belt has been shown to originate primarily from the Salinas River, approximately $10 \mathrm{~km}$ to the east-northeast of our study site. We have shown that the internal tides do not exhibit preferred directionality, and thus the net transport is driven by the low-frequency flow, which is predominantly along-shelf, and dominated by wind-driven dynamics.

\section{Conclusions}

Variability of the internal tide on the mid-continental shelf south of Monterey Submarine Canyon in Monterey Bay during summer months appears to be driven primarily by changes in the water column density structure, driven by upwelling and relaxation associated with along-coast winds. Resuspension of fine-grained sediment on the outer mud-belt only occurs when long-period surface waves coincide with enhanced near-bottom flow due to either the internal tide or strong along-shelf flow associated with relaxation events in the wind field. Thus, the internal tide alone is not energetic enough to resuspend and transport the fine-grained sediments found on this portion of the shelf. The internal tides do not exhibit preferred directionality at our site in $90 \mathrm{~m}$ water depth, and therefore do not contribute to net suspended sediment flux; instead, observed net transport of suspended matter is down-coast, consistent with dominant subtidal circulation.

\section{Acknowledgements}

This project was funded by the U.S. Geological Survey's Coastal and Marine Geology Program. We thank C. Hunter, T. Elfers, P. Dal Ferro, J. White, and J. Ferreira for their role in the deployment and recovery of the tripod and mooring. We thank Chris Sherwood for his expert advice on the application of the sediment transport model. B. Edwards and J. Reid supplied the mud belt sediment distribution data and N. Golden assisted with the mapping of this data. We thank the captain and crews of the $R / V$ Pt Sur 
who assisted with field operations (vessel time was funded by the National Science Foundation grant OCE0961810 to McPhee-Shaw, Bellingham, Shaw, and Stanton). We thank Thomas Connolly for his timely review and useful comments on a draft of the manuscript. Use of trademark names does not imply U.S. government endorsement of products. 


\section{References}

Carter, G.S., Gregg, M.C. and Lien, R.C., (2005) Internal Waves, solitary-like waves, and mixing on the Monterey Bay shelf, Continental Shelf Research, 25, 1499-1520.

Carter, G.S. (2010) Barotropic and Baroclinic $\mathrm{M}_{2}$ Tides in the Monterey Bay Region, Journal of Physical Oceanography, 40 (8), 1766-1783.

Cacchione, D. and Drake D. (1986) Nepheloid Layers and Internal Waves over Continental Shelves and Slopes, Geo Marine Letters, 6 (3), 147-152.

Cacchione, D., Drake D., Ferreira, J.T. and Tate, G.B. (1994) Bottom Stress Estimates and Sand Transport on the Northern California Inner Continental Shelf, Continental Shelf Research, 14 (10/11), 1273-1289.

Cheriton, O. M., E. E. McPhee-Shaw, W. J. Shaw, T. P. Stanton, J. G. Bellingham, and C. D. Storlazzi (2014) Suspended particulate layers and internal waves over the southern Monterey Bay continental shelf: An important control on shelf mud belts?, J. Geophys. Res. Oceans, 119, 428-444, doi:10.1002/2013JC009360.

Collins, C.A., Margolina, T., Rago, T.A. and Ivanov, L. (2013) Looping RAFOS floats in the California Current System, Deep-Sea Research II, 85 (C), 42-61.

Drake, David E. and Cacchione, David A. (1987) Suspended Particulate Matter Along the Coastal Ocean Dynamics Experiment Line During Upwelling and Relaxation Events, Journal of Geophysical Research, 92 (C2), 1699-1707.

Edwards, B. (2002) Variations in sediment texture on the northern Monterey Bay National Marine Sanctuary continental Shelf, Marine Geology, 181 (1-3), 83-100.

Ferre ,B., Sherwood, C.R., Wiberg, P.L. (2010) Sediment Transport on the Palos Verdes Shelf, Continental Shelf Research, 30 761-780.

Gill, A.E (1982) Atmosphere Ocean Dynamics, Academic Press: New York, 662p, ISBN 0-12-283522-0.

Griggs, G.B. and Hein, J.R. (1980) Sources, dispersal and clay mineral composition of fine-grained sediment off central and northern California, Journal of Geology, 88, 541-566. 
Gust, G., Muller, V., (1997) Interfacial hydrodynamics and entrainment functions of currently used erosion devices. In: Burt, N. (Ed.), Cohesive Sediments. Wiley, Chichester, UK, pp. 149-174.

Hall, R.A., Huthance, J.M., and Williams, R.G. (2014a) Internal wave reflection on shelf slopes with depth-varying stratification, Journal of Physical Oceanography, 43, 248-258.

Hall, R.A., Alford, M.H., Carter, G.S., Gregg, M.C., Lien, R.C., Wain, D.J., and Zhao, Z.X. (2014b) Transition from partly standing to progressive internal tides in Monterey Submarine Canyon, Deep-Sea Research II, 104, 164-173.

Harris, C.K., Wiberg, P.L., (1997) Approaches to quantifying long-term continental shelf sediment transport with an example from the northern California STRESS midshelf site. Continental Shelf Research 17, 1389-1418.

Hickey, B.M. (1979) The California Current System - hypotheses and facts. Progress in Oceanography, 8 (4) pp. 191-279.

Jachec, S.M. (2012) Power Estimates Associated With Internal Tides From the Monterey Bay Area. Oceanography vol. 25 (2) pp. 52-55

Johnston, T. M. S., D. L. Rudnick, G. S. Carter, R. E. Todd, and S. T. Cole (2011) Internal tidal beams and mixing near Monterey Bay, J. Geophys. Res., 116, C03017, doi:10.1029/2010JC006592.

Kang, D. and Fringer, O. (2012) Energetics of Barotropic and Baroclinic Tides in the Monterey Bay Area, Journal of Physical Oceanography, 42 (2), 272-290.

Kerry, C.G., Powell, B.S. and Carter, G.S. (2014) The Impact of Subtidal Circulation on Internal Tide Generation and Propagation in the Phillipine Sea, Journal of Physical Oceanography, 44 (5), 1386-1405.

Kunze, E., Rosenfeld, L.K., Carter, G.S., and Gregg, M.C. (2002) Internal Waves in Monterey Submarine Canyon, Journal of Physical Oceanography, 32 (6), 18901913.

Lentz, S.J., (1994) Current dynamics over the Northern California Shelf. Journal of Physical Oceanography 24, 2461-2478. 
Madsen, O.S., (1994) Spectral wave-current bottom boundary layer flows. Coastal Engineering 1994. In: Proceedings, 24th International Conference Coastal Engineering Research Council, pp. 384-398.

McManus, M.A., Cheriton, O.M., Drake, P.J., Holliday, D.V., Storlazzi, C.D., Donaghay, P.L., Greenlaw, C.F. (2005) Effects of physical processes on structure and transport of thin zooplankton layers in the coastal ocean, Marine Ecology Progress Series, 301, 199-215.

Nash, J.D., E.L. Shroyer, S.M. Kelly, M.E. Inall, T.F. Duda, M.D. Levine, N.L. Jones, and R.C. Musgrave (2012) Are any coastal internal tides predictable? Oceanography 25(2):80-95, http://dx.doi.org/ 10.5670/oceanog.2012.44.

Noble, M.N. and Xu, J.P (2003) Observations of large amplitude cross-shore internal bores near the shelf break, Santa Monica Bay, CA, Marine Environmental Research, 56, pp. 127-149.

Noble, M.N, Rosenberger, K.J, Xu, J.P., Signell, R.P. and Steel, A. (2009a) Connections Among the Spatial and Temporal Structures in Tidal Currents, Internal Bores, and Surfcial Sediment Distributions Over the Shelf off Palos Verdes, California, U.S. Geological Survey Scientific Investigations Report, 2008-5094, 41 p., available at http://pubs.usgs.gov/sir/2008/5094.

Noble, M.N., Jones B., Hamilton, P., Xu, J.P., Robertson, G., Rosenfeld, L and Largier, J. (2009b) Cross-shelf transport into nearshore waters due to shoaling internal tides in San Pedro Bay, CA, Continental Shelf Research, 29 (15), pp. 1768-1785.

Pawlowicz, R., Beardsley, B., and Lentz, S. (2002) Classical tidal harmonic analysis including error estimates in MATLAB using T_TIDE, Computers and Geosciences, 28, pp. 929-937.

Petruncio, E.T., Rosenfeld, L., Paduan, J.D. (1998) Observations of the Internal Tide in Monterey Canyon. Journal of Physical Oceanography, 10, pp. 1873-1903

Rainville, L. and Pinkel, R. (2006) Propagation of Low-Mode Internal Waves through the Ocean, Journal of Physical Oceanography, 36 (7), pp. 1220-1236.

Ramp, S., Paduan, J.D., Shulman, I., Kindle, J., Bahr, F.L., and Chavez, F. (2005) Observations of upwelling and relaxation events in the northern Monterey Bay during August, 2000, Journal of Geophysical Research, 110, (C07013), 21p. 
Rosenberger, K.J., Noble, M.A., Sherwood, C.R., Martini, M.M., Ferreira, J.T., and Montgomery, E (2011) Palos Verdes Shelf oceanographic study; data report for observations December 2007-April 2008: U.S. Geological Survey Open-File Report 2010-1240, 118 p., available at http://pubs.usgs.gov/of/2010/1240/.

Shanks, A.L., Morgan, S.G., MacMahan, J., Reniers, Ad.J.H.M., Reniers, M., Brown, J., Fujimura, A., Griesemer, C. (2014) Onshore transport of plankton by internal tides and upwelling-relaxation events. Marine Ecology Progress Series, 502 (15), pp. 39-51.

Shaw, W.J. and Trowbridge, J.H. (2001) The direct estimation of near-bottom turbulent fluxes in the presence of energetic wave motions. Journal of Atmospheric and Oceanic Technology, 18 (9) 1540-1557.

Smith, D.J., and McLean, S.R. (1977) Spatially averaged flow over a wavy surface. Journal of Geophysical Research, 82 (12), pp. 1735-1746.

Storlazzi, C.D., McManus, M.A., Figursky, J.D. (2003) Long-term, high-frequency current and temperature measurements along central California: insights into upwelling/relaxation and internal waves on the inner shelf. Continental Shelf Research, 23 pp. 901-918

Van Aken, H.M, van Haren, Hans, and Maas, Leo R.M. (2007) The high-resolution vertical structure of internal tides and near-inertial waves measured with an ADCP over the continental slope in the Bay of Biscay, Deep Sea Research I, 54, pp. 533-556.

Wain, D.J, Gregg, M.C., Alford, M.H., Lien, R-C., Hall, R.A. and Carter, G.S. (2013) Propagation and dissipation of the internal tide in upper Monterey Canyon, Journal of Geophysical Research, 118, pp. 4855-4877.

Walter, R.K., Woodson, B.C., Arthur, R.S., Fringer, O.B., and Monismith, G. (2012) Nearshore internal bores and turbulent mixing in southern Monterey Bay. Journal of Geophysical Research, 117 (C7) C07017

Wang, Q., Kalogiros, J.A., Ramp, S.R., Paduan, J.D., Buzorius, G., and Jonsson, H. (2011) Wind Stress Curl and Coastal Upwelling in the Area of Monterey Bay Observed during AOSN-II, Journal of Physical Oceanography, 41 (5), pp. 857877. 
Wiberg, P.L., Harris, C.K. (2002) Desorption of p,p0-DDE from sediment during resuspension events on the Palos Verdes Shelf, California: a modeling approach. Continental Shelf Research 22 (6-7), pp. 1005-1023.

Wiberg, P.L., Smith, J.D. (1987) Calculations of the critical shear stress for motion of uniform and heterogeneous sediments. Water Resources Research 23, pp. 14711478.

Wiberg, P.L., Drake, D.E., Cacchione, D.A. (1994) Sediment resuspension and bed armoring during high bottom stress events on the northern California inner continental shelf: measurements and predictions. Continental Shelf Research 14 (10/11), pp. 1191-1219.

Wiberg, P.L., Drake, D.E., Harris, C.K., Noble, M. (2002) Sediment transport on the Palos Verdes shelf over seasonal to decadal time scales. Continental Shelf Research 22 (6-7), pp. 987-1004.

Wiberg, P.L., Sherwood, C.R. (2008) Calculating wave-generated bottom orbital velocities from surface wave parameters. Computers and Geosciences 34, 12431262, doi:10.1016/j.cageo.2008.02.010.

Woodson, C.B., Barth, J.A., Chertiton, O.M., McManus, M.A., Ryan, J.P., Washburn, L., Carden, K.N., Cheng, B.S., Fernandes, J., Garske, L.E., Gouhier, T.C., Haupt, A.J., Honey, K.T., Hubbard, M.F., Iles, A., Kara, L., Lynch, M.C., Mahoney, B., Pfaff, M. Pinsky, M.L., Robart, M.J., Stewart, J.S., Teck, S.J., and True, A. (2011) Observations of internal wave packets propagating along-shelf in northern Monterey Bay. Geophysical Research Letters, 38 (1), L01605.

Wunsch, C. (1969) Progressive Internal Waves on Slopes, J. Fluid Mechanics, 35, pp. 131-144.

Wunsch, C. (1975) Internal Tides in the Ocean, Reviews of Geophysics and Space Physics, 13 (1), pp. 167-182.

$\mathrm{Xu}$, J.P (1999) Local wave climate and long-term bed shear stress characteristics in Monterey Bay, CA. Marine Geology, 159 (1-4), pp. 431-353.

Xu, J.P, Noble, M.N. and Eittreim, S.L., (2002), Suspended sediment transport on the continental shelf near Davenport, California. Marine Geology, 181 (1-3), pp. 171194. 
Xu, J. P., M. Noble, S. L. Eittreim, L. K. Rosenfeld, F. B. Schwing, and C. H. Pilskaln (2002) Distribution and transport of suspended particu- late matter in Monterey Canyon, California, Mar. Geol., 181, pp. 215- 234.

Xu, J. P., and M. A. Noble (2009) Currents in Monterey Submarine Canyon, J. Geophys. Res., 114, C03004, doi:10.1029/2008JC004992.

Zhao, Z.X., Alford, M.H., Lien, R.C., Gregg, M.C., and Carter, G.S. (2012) Internal Tides and Mixing in a Submarine Canyon with Time-Varying Stratification. Journal of Physical Oceanography, 42, pp. 2121-2142. 


\section{Figure Captions}

Figure 1. Map of Monterey Bay, California showing location of the study site (S90) on the southern shelf, as well as the offshore NOAA 46042 buoy (square). The approximate location of the mid-shelf mud belt is indicated by the orange overlay (data originally published in Edwards [2002]). Black bathymetric contours are in 10-m increments from 0 to $120 \mathrm{~m}$, and gray contours are in 100-m increments from 200 to $2000 \mathrm{~m}$. The inset map shows location of Monterey Bay along the coast of California, USA

Figure 2. Wind and water-column data from the deployment period. a) Wind vectors (black, 1 vector every $6 \mathrm{~h}$ ) and along-coast wind velocity component (blue, hourly) from NOAA buoy 46042 (positive values are down-coast, and thus upwelling favorable). b) Water column temperature data from thermistor string at 90-m water depth. Temperatures range from 8 to $16^{\circ} \mathrm{C}$. c) Along-shelf and d) cross-shelf subtidal flow at near-surface (red), upper-middle (magenta), lower-middle (cyan), and near-bottom (blue) depths. Positive along-shelf values are poleward, and positive cross-shelf values are onshore.

Figure 3. Variance preserving spectra of the subtidal water column currents at several depth levels. a) Along-shelf component. b) Cross-shelf component. c) Counter-clockwise rotary component and d) Clockwise rotary component.

Figure 4. Vertical profiles of velocity variance. a) Variance of the internal tide for alongshelf (blue) and cross-shelf flow. b) Percentage of variance of the total record for crossshelf (red) and along-shelf (blue) internal tides versus the barotropic tide (black).

Figure 5. Contoured time series of water column temperature (a) and internal tide speed (b). Periods of enhanced internal tidal activity are outlined and labeled for individual examination.

Figure 6. Contoured time series of along-shelf (a) and cross-shelf (b) internal tidal currents for the period extending from Year Day 215 to Year Day 220, corresponding to period E in Figure 5. 
Figure 7. Surface waves, near-bottom currents, suspended sediment and stress. a) Significant wave height (black) and peak period (green) from NOAA buoy 46042. b) Near-bottom burst averaged current speed measured by the ADV at 0.5 mab (black), near-bottom wave-orbital current speed as calculated from surface wave parameters and near-bottom internal tide speed from the first bin of the ADCP at 7 mab (cyan). c) Nearbottom suspended sediment data from the transmissometer (black) and OBS (red). d.) Stresses computed from the sediment transport model. Combined wave-current stress (blue), current stress (cyan), and wave stress (red). The critical-shear stress for the finegrained sediment fraction is denoted by the dashed line.

Figure 8. Suspended sediment, stress, and forcing during a resuspension event. a) Suspended sediment as measured by transmissometer (red), optical backscatter (cyan) and as modeled by the 1-D model (blue). b) Modeled bottom stress for waves (red), currents (cyan), and combined waves and currents (blue). c) Near-bottom current speed (blue) and direction (green) as measured by the ADV. d) Significant wave height (blue) and peak wave period (green) measured by NOAA buoy 46042.

Figure 9. Profiles of Brunt-Väisälä frequency for various periods of observed enhanced internal tide activity; thin grey lines are tidal averages, thick grey line is the average profile for the entire dataset, and the thick black line is the average for the period of interest. Each panel corresponds to a period outlined in Figure 5. a) Year Day 125-130. b) Year Day 143-148. c) Year Day 158-163. d) Year Day 182-187. e) Year Day 215-220. f) Year Day 291-296.

Figure 10. Comparison between near-bottom stress due to internal tides (solid line) and low-frequency flow (dashed line). 
Table 1 - Instrumentation, depths, and sampling intervals used in this study.

\begin{tabular}{lccc}
\hline Platform & Instrument & $\begin{array}{c}\text { Depth } \\
(\mathrm{m})\end{array}$ & $\begin{array}{c}\text { Sampling Interval } \\
(\mathrm{s})\end{array}$ \\
\hline Mooring & $\begin{array}{c}\text { Seabird SBE-37 Microcat } \\
\text { temperature/salinity sensor }\end{array}$ & 20 & 180 \\
& & & \\
Mooring & RBR TR-1060 temperature sensor & $30,40,50$, & 30 \\
& & $60,70,80$ & 180 \\
Tripod & RDI 300 kHz ADCP & 86 & 180 \\
Tripod & $\begin{array}{c}\text { Seabird SBE-37 Microcat } \\
\text { temperature/salinity sensor } \\
\text { Tripod }\end{array}$ & 87 & 180 \\
\hline \hline
\end{tabular}

Table 2 - Grain-size distribution by mass of surface sediment at the study site.

\begin{tabular}{ccccc}
\hline $\begin{array}{c}\text { Coarse Sand } \\
(1000-250 \mu \mathrm{m})\end{array}$ & $\begin{array}{c}\text { Fine Sand } \\
(250-63 \mu \mathrm{m})\end{array}$ & $\begin{array}{c}\text { Coarse Silt } \\
(63-16 \mu \mathrm{m})\end{array}$ & $\begin{array}{c}\text { Fine Silt } \\
(16-4 \mu \mathrm{m})\end{array}$ & $\begin{array}{c}\text { Clay } \\
(<4 \mu \mathrm{m})\end{array}$ \\
\hline $0.01 \%$ & $6.79 \%$ & $41.98 \%$ & $25.94 \%$ & $25.28 \%$ \\
\hline \hline
\end{tabular}


figure 1

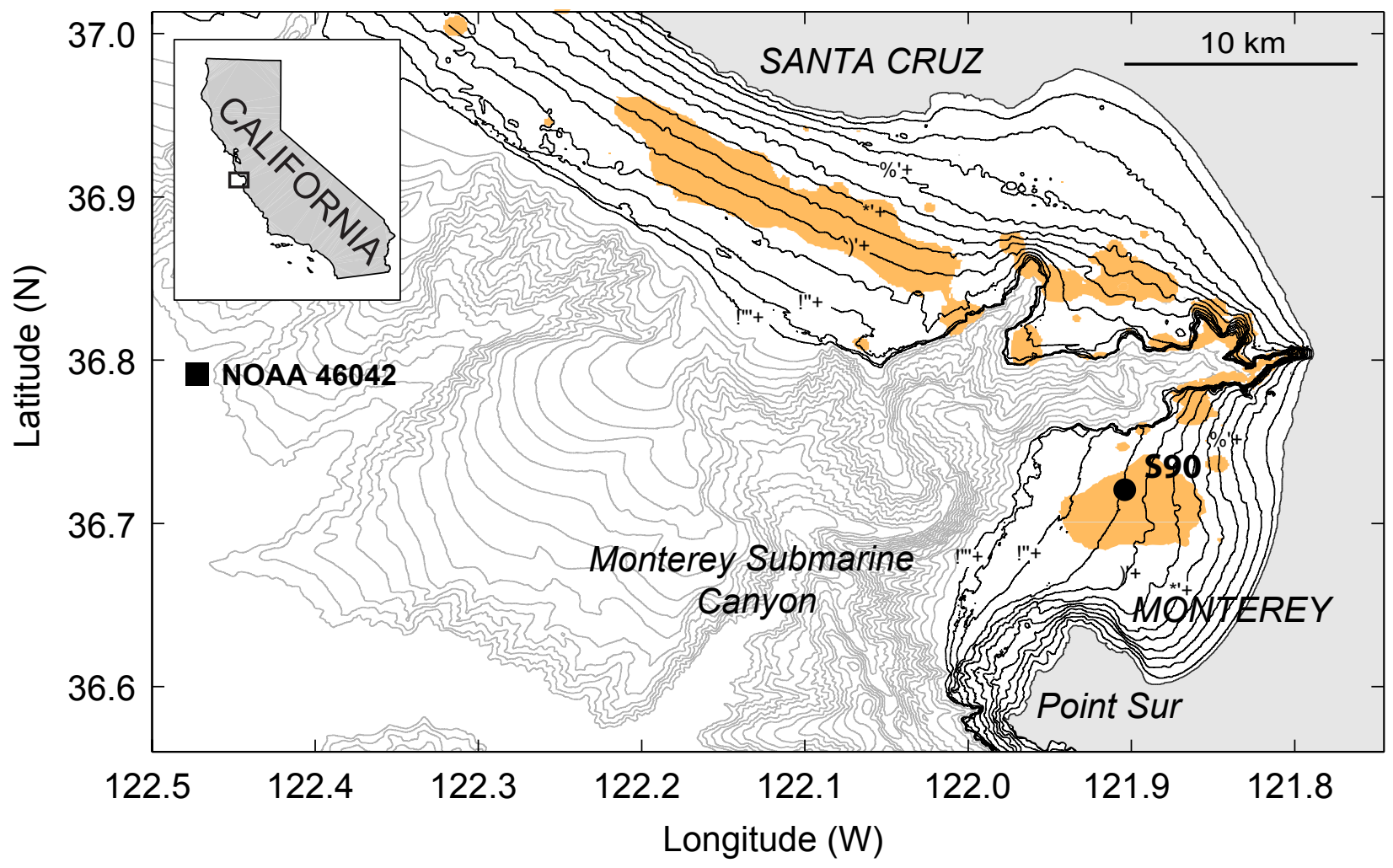


figure 2
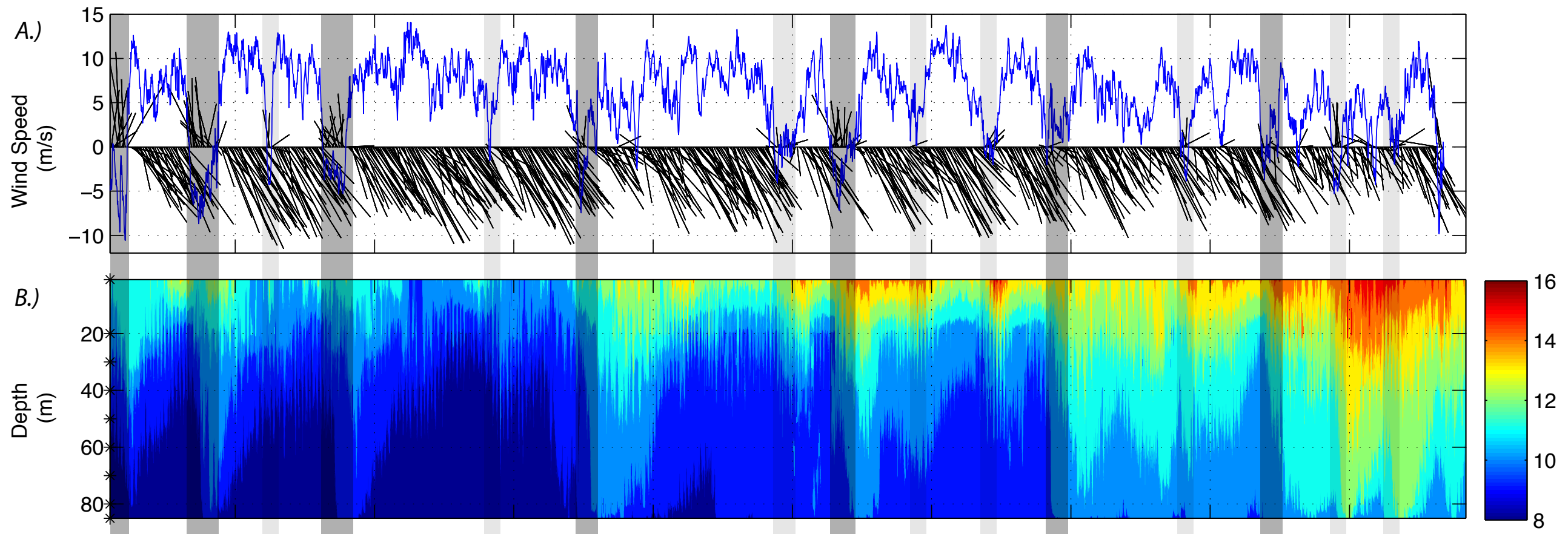

c.)

D.

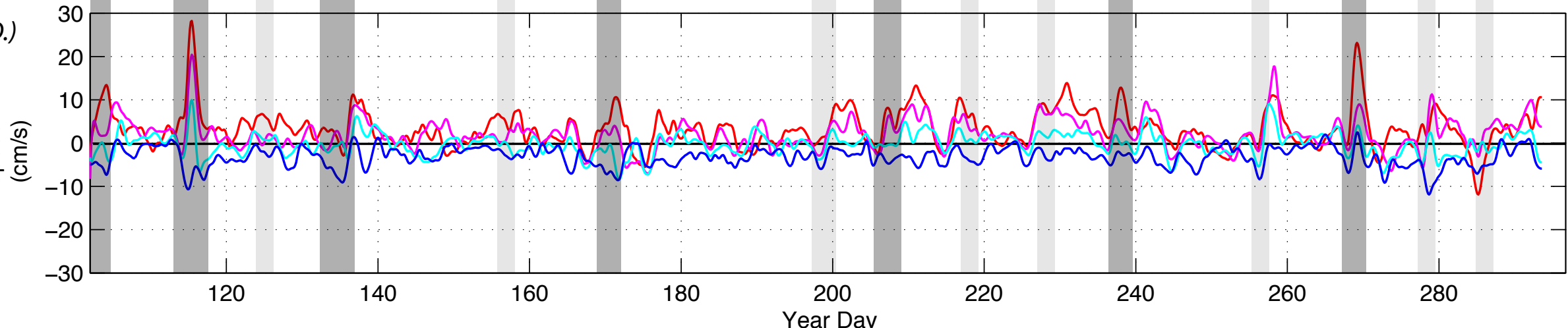


figure 3
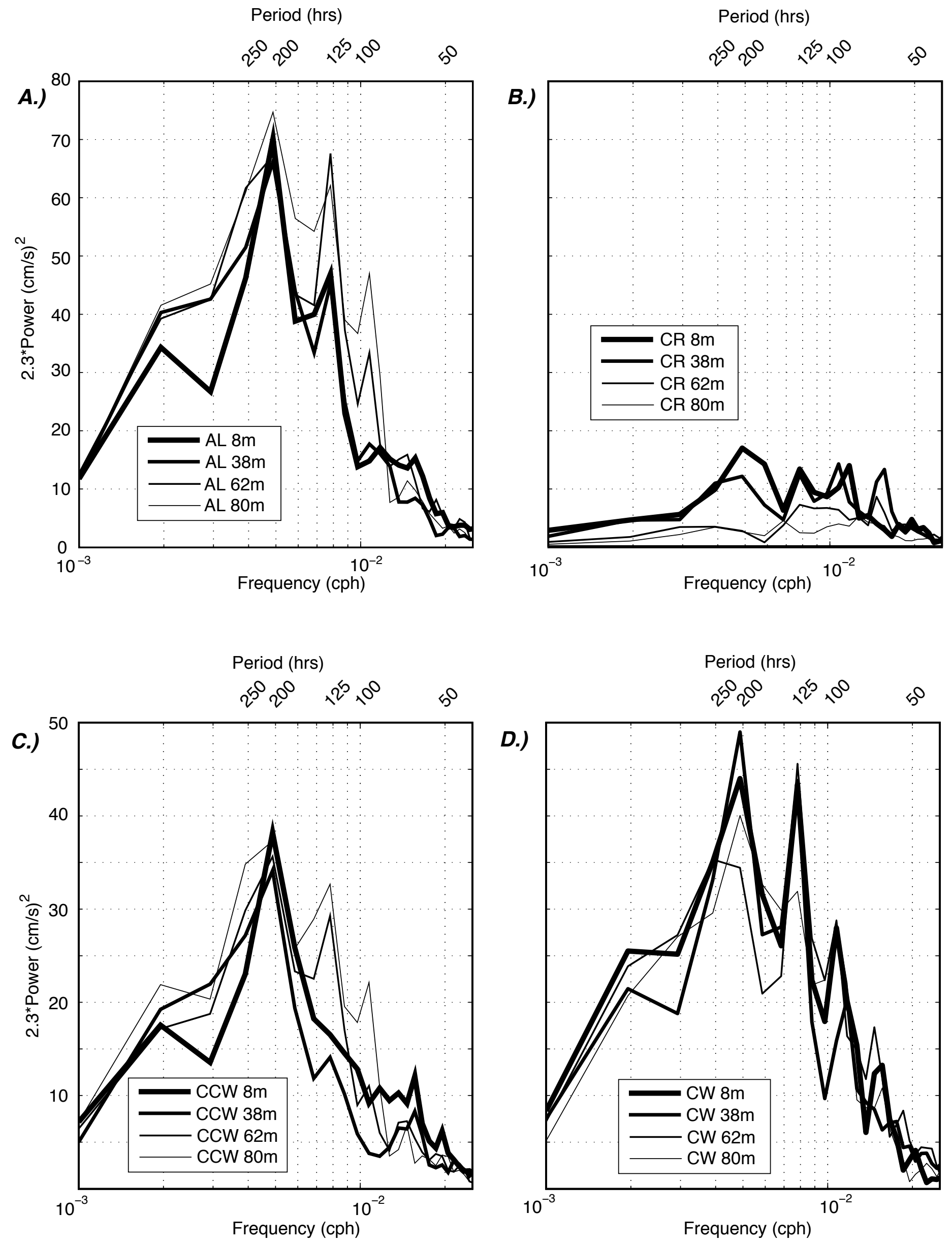
figure 4
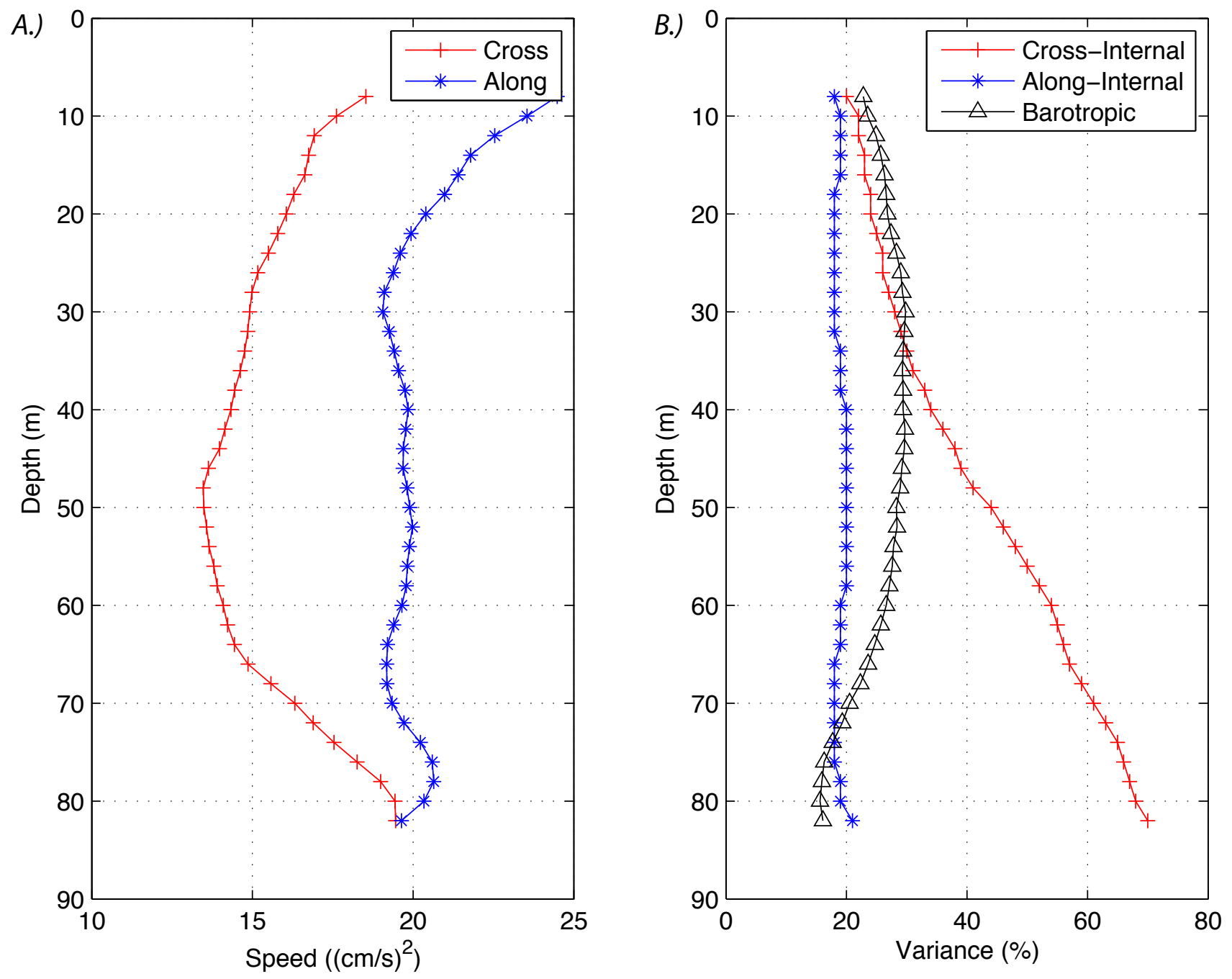
figure 5

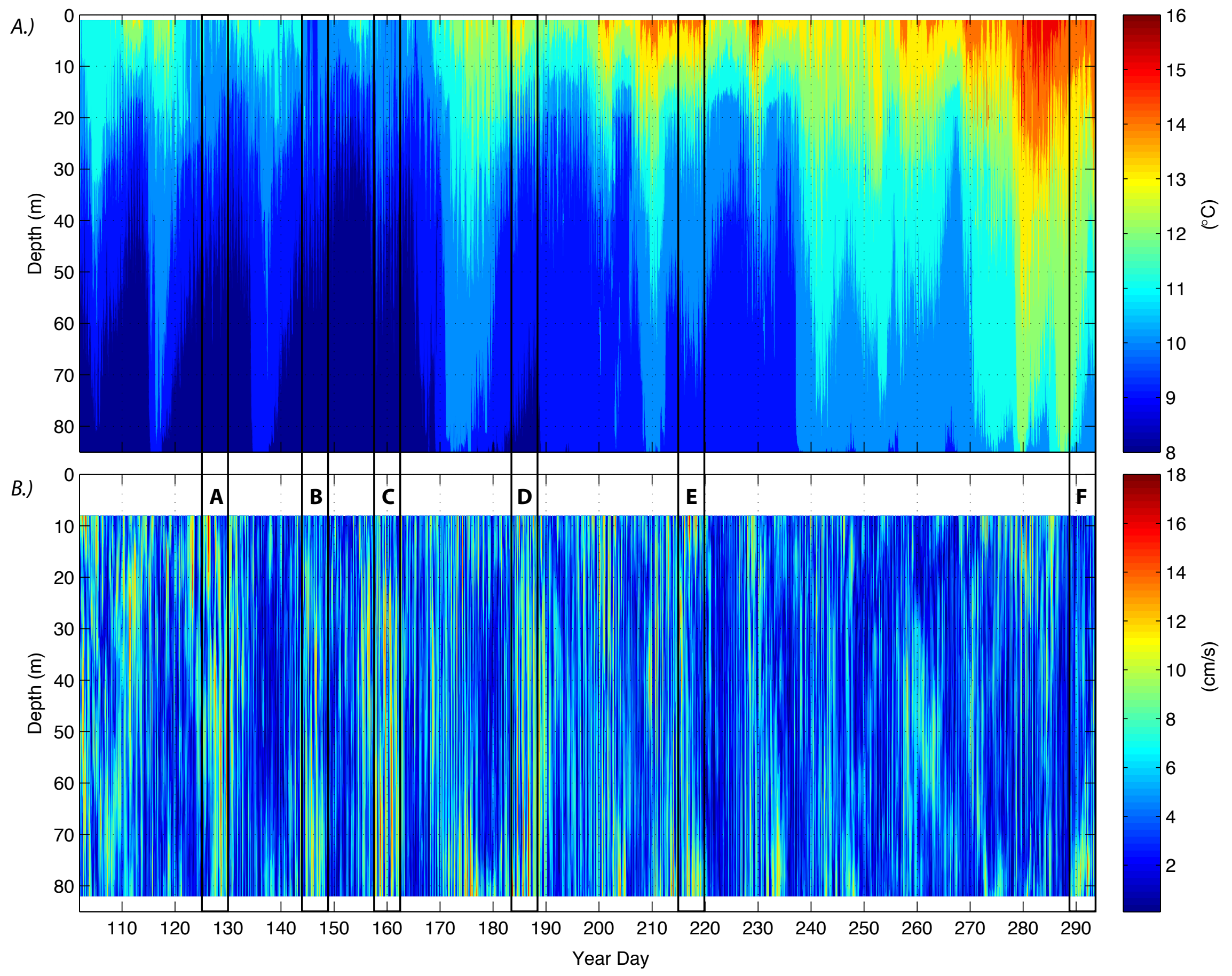


figure 6
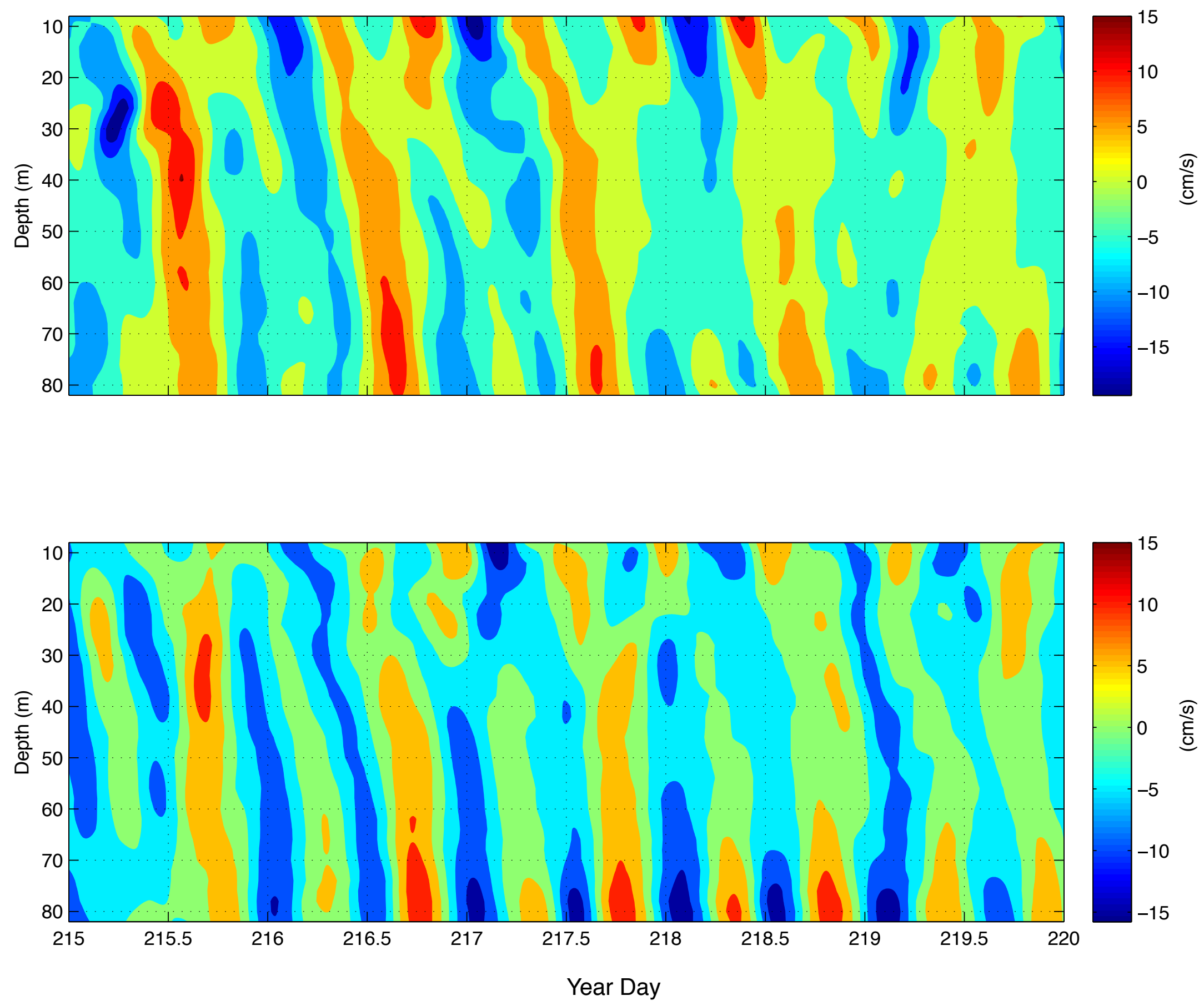
figure 7

A.)
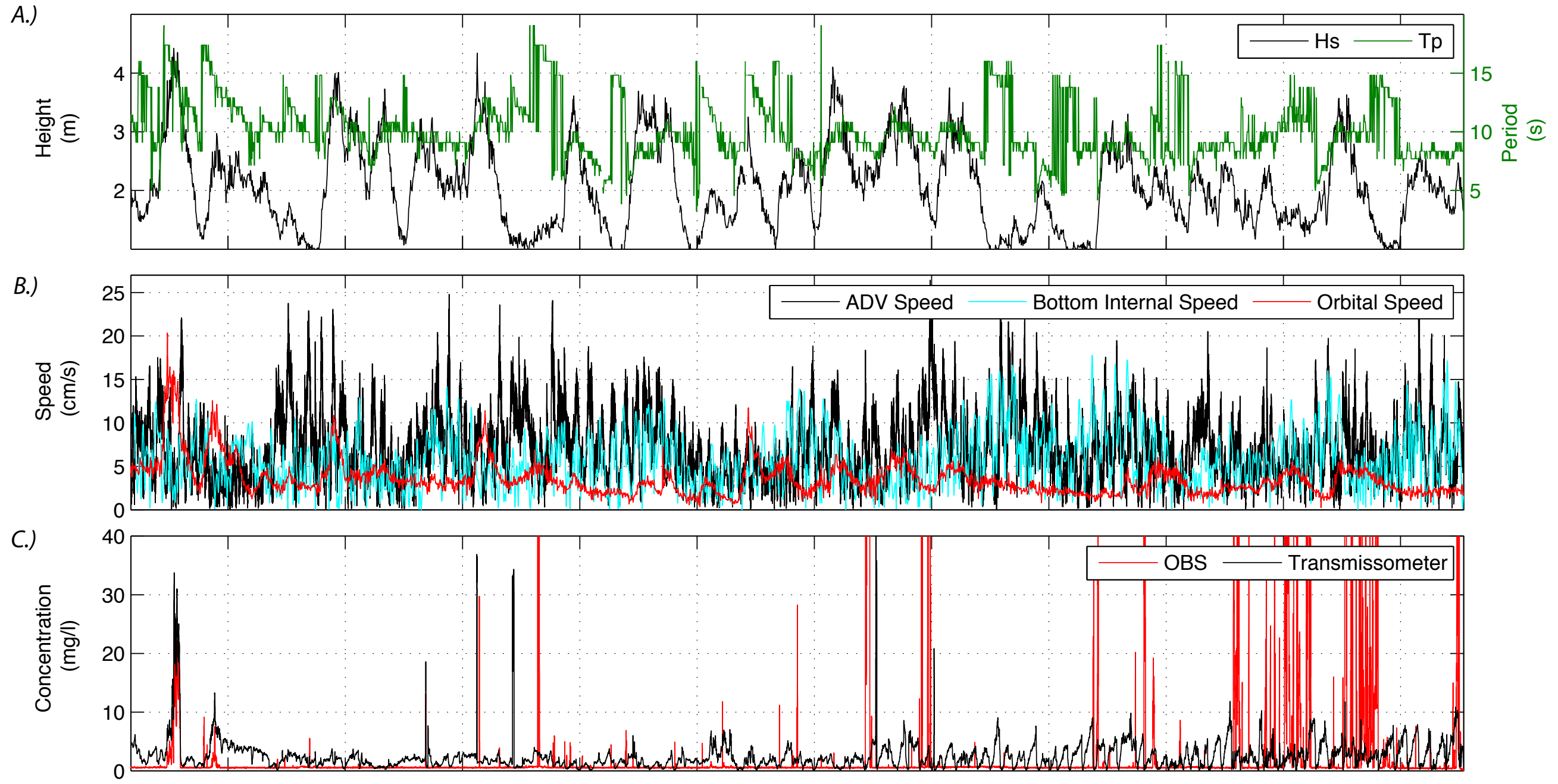

D.)

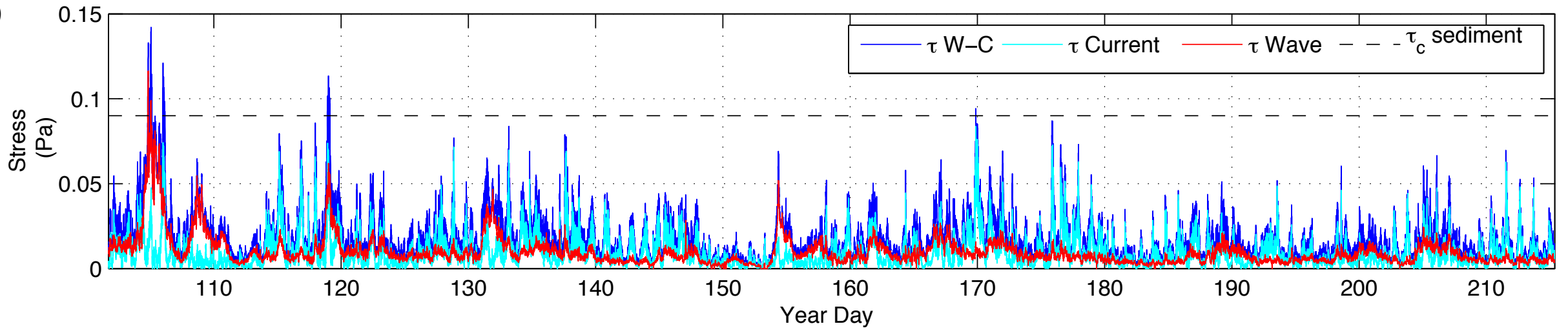


figure 8

A.)

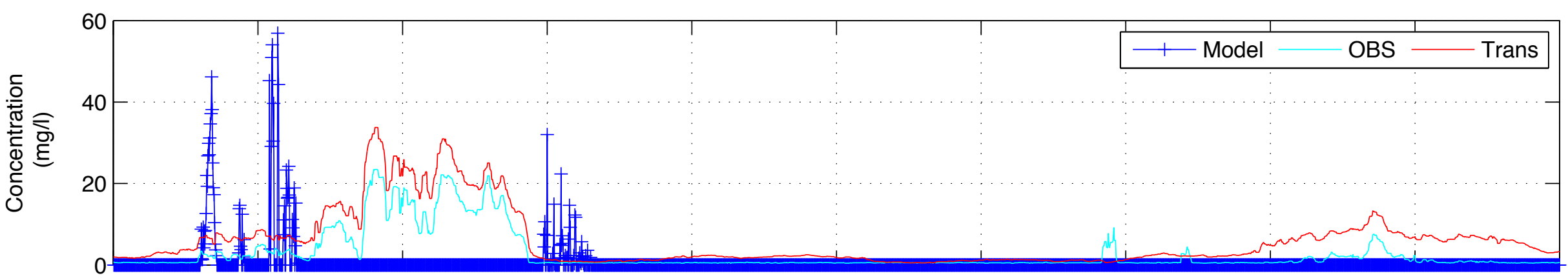

B.)

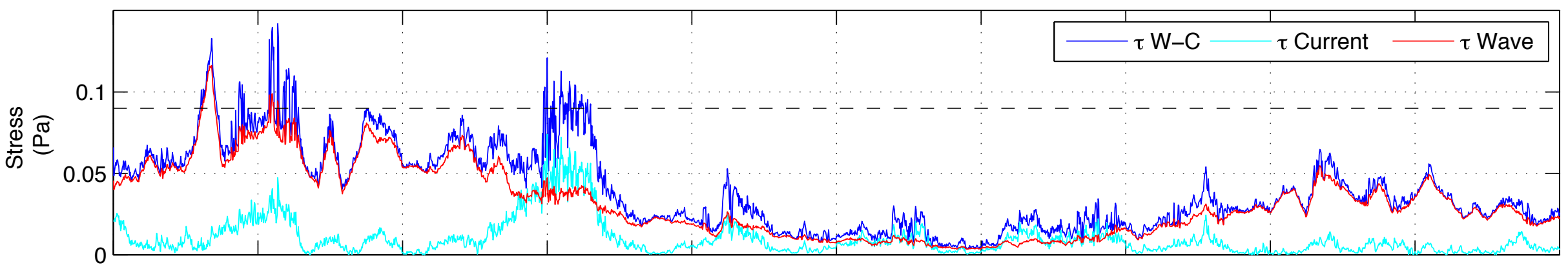

C.)

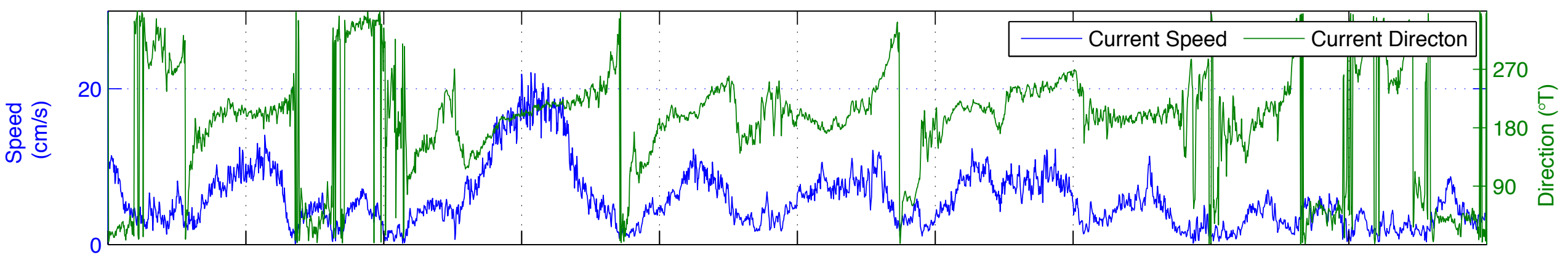

D.)

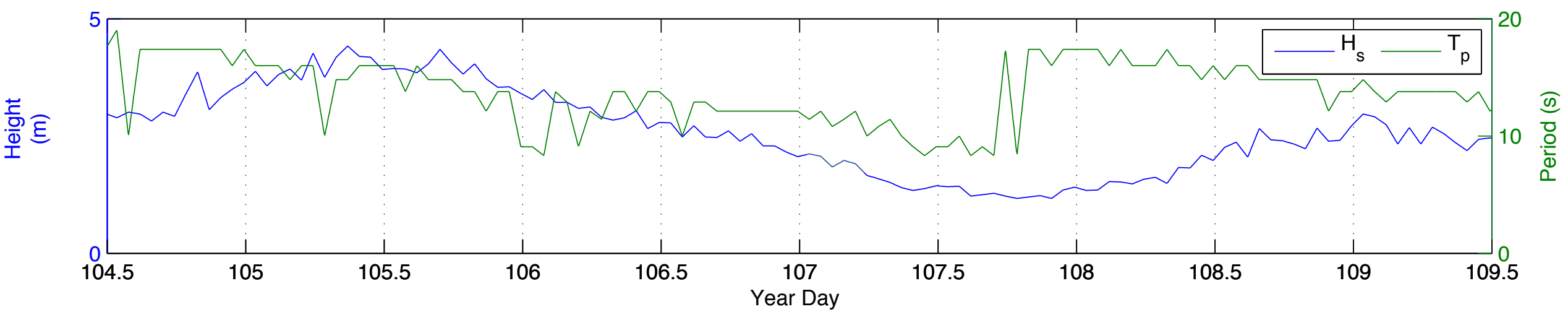


figure 9
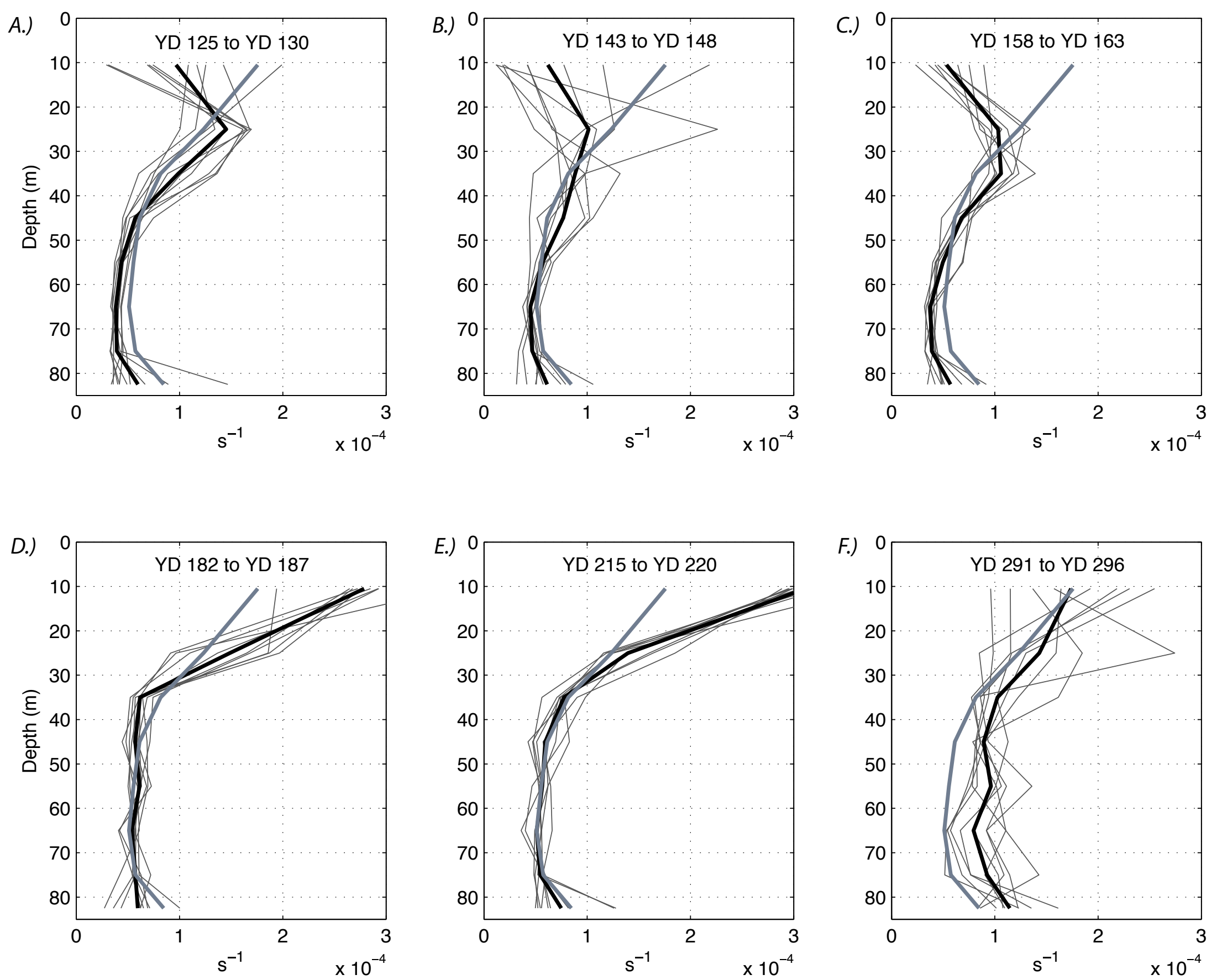
figure 10

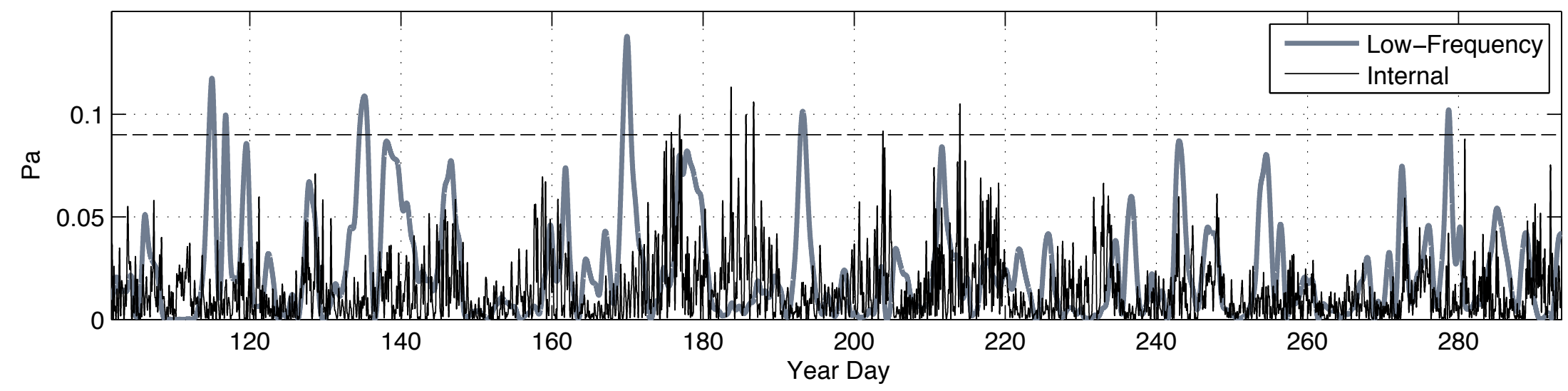

